1 Combs CD. Our nation today and in 2020:are we preparing the health professionals that we will need? Factors affecting the health workforce. Washington, DC: Association of Academic Health Centres, 2006.

2 Toffler A. Future shock. New York: Bantam Books, 1970.

3 Carroll F. A Harvard doctor doing research at the lab hopes to market a new way to remove acne and body fat. Daily Press 13 Apr 2006; A: 1 .

Grenda E. Castle Island's worldwide guide to rapid prototyping. Medica applications of rapid prototyping: tutorial section. May 2005. home.att.net/ $\sim$ castleisland/med lks.htm.

5 Davis J. Microbubbles' fantastic voyage. Wired 2006;11:40.

6 Drake RR, Deng Y, Schwegler EE, Gravenstein S. Proteomics for biodefense applications: progress and opportunities. Expert Rev Proteomics 2005;2:1-11.

7 Lymberis A, Olsson S. Review. Intelligent biomedical clothing for personal health and disease management: state of the art and future personal health and disease managem
vision. Telemed J E Health 2003;9:379-86.

8 L'Heureux N, Dusserre N, Konig G, Victor B, Keire P, Wight TN, et al. Human tissue-engineered blood vessels for adult arterial revascularization. Nat Med 2006;12:361-5.

9 Atala A. Tissue engineering, stem cells and cloning: current concepts and changing trends. Second conference on strategies for engineered negligible senescence (SENS), Cambridge, 7 Sep 2005. www.gen.cam.ac.uk/sens2/abs/Atala.htm.

10 Gorss J. Researchers develop "natural bandages" that mimic body's healing process. Eurekalert 10 Feb 2003. www.eurekalert.org/pub_releases/ 2003-02/acs-rd021003.php\#.

11 McGowan Institute for Regenerative Medicine. Institute collaborates with National Tissue Engineering Center: internationally recognized tissue engineer- ing scientist associates with McGowan Institute. www.mirm.pitt.edu/news/ article.asp?qEmpID =100.

12 Nanosheets that mimic protein formation made by researchers. Medical News Today 15 Oct 2006. www.medicalnewstoday.com/ medicalnews.php?newsid $=54072$.

13 Beth Israel Deaconess Medical Center. New radio wave treatment to correct back disorders offers alternative to drugs, open-spine surgery. 14 May 2002. www.bidmc.harvard.edu/tools/newsnow/pr_out.asp?pr_id $=307$.

14 Kolb JF. Pulsed power and plasma for medical and environmental applications. Nuclear and Plasma Sciences Society News September 2006.3.30-1. wwwieee org/organiza

www.iee.org/organizations/pubs/newsletters/npss/0906/pulded.html. Nanotechnology. MIT material stops bleeding in seconds.
nanotechnology.com/news/?id $=9174$. nanotechnology.com/news/?id $=917$

16 Stereolithography. Stereolithography made easy. What is rapid prototyping? www.stereolithography.com/rapidprototyping.php.

17 InTouch Technologies. Virtually there technology. intouchhealth.com/ products-RP7.html\#virtual.

18 Gallagher A, Cates C. Approval of virtual reality training for carotid stenting, what this means for procedural-based medicine. JAMA 2004;292:3024-6.

19 Schmidt EA, Scerbo MW, Bliss JP, Hanner-Bailey HS, Garcia HM, Weireter LJ Jr. Surgical skill performance under combat conditions in a virtual environment. In: Human Factors and Ergonomics Society 2006. Provirtual environment. In: Human Factors and Ergonomics Society 2006. Pro-
ceedings of the Human Factors and Ergonomics Society 50th annual meeting, 16-20 Oct 2006; San Francisco, CA; Santa Monica, CA: HFES, 2006:2697-701.

doi $10.1136 /$ bmj.39049.453877.BE

\title{
Back to the future: how good are doctors at gazing in the crystal ball?
}

\author{
Rob Stepney
}

Twenty years ago, in a study commissioned by the Bristol-Myers company, 227 of the world's leading clinical scientists were asked to predict the state of medicine in the early 21 st century. ${ }^{1}$ The success of the 1986 predictions, or lack of it, may tell us the likely value of current attempts to foresee the speed and nature of medical advance: sometimes you have to look back to look forwards.

The scientists interviewed came from 10 countries (13 were from the United Kingdom), but most were based in the United States, so the US is usually the reality against which I test their predictions.

\section{Curing cancer}

Back in 1986, all the buzz was in biological response modifiers. We were going to dissect out elements of the immune response, amplify them, and set them to work on tumours with devastating effect. Of course, it came to very little: interleukins, interferons, and even tumour necrosis factor proved sadly ineffective against common solid tumours and were unexpectedly toxic when given in pharmacological doses. In the mid-1980s there was great, if misplaced, faith in these agents. Despite this, future rates of cure were predicted accurately.

The pollsters told the specialists they interviewed that "the average cure rate for cancer patients of all types" was about $50 \%$. They then asked what it would be in the year 2000. Estimates ranged from no change to $90 \%$, with a median of $65 \%$. Currently, the Centers for Disease Control say that the overall five year survival rate for adults diagnosed with cancer in 1997 2002 is $65 \%{ }^{2}$

Of course, surviving five years from diagnosis does not actually equal "cure": screening or improved diagnostics may simply start the survival clock earlier in the

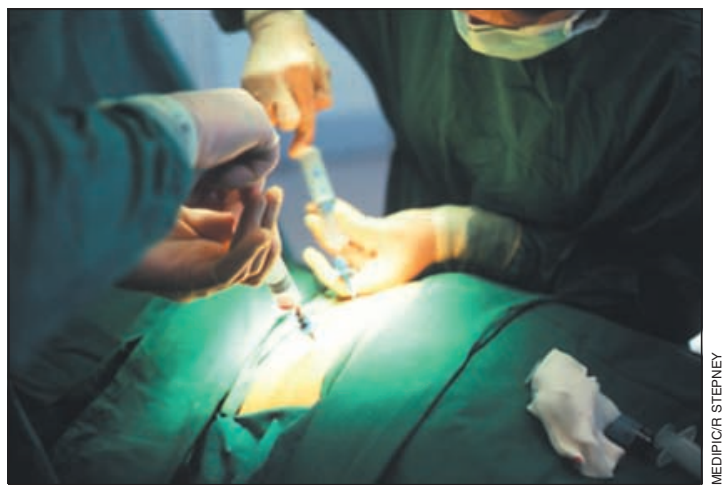

Charlbury

OX7 3HJ

Rob Stepney freelance medical and science writer walcot2@ freenetname.co.uk

BMJ 2006;333:1311-3 one of oncology's "piecemeal" advances

course of a disease that will ultimately be fatal. But calculating five year survival rates is standard practice in oncology, so the specialists in 1986 were probably using the "five year equals cure" convention when making their estimates.

Interviewees were also accurate in distinguishing between tumours for which survival would improve (haematological malignancies and breast, prostate, and ovarian cancers) and those for which it would not (cancers of the lung, liver, stomach, and pancreas, and malignant brain tumours). ${ }^{3}$ The only big improvement they missed was in colorectal cancer.

Paradoxically, the specialists interviewed were wide of the mark when asked which treatments would be responsible for this improved outcome. Trastuzumab (Herceptin) and bevacizumab (Avastin) notwithstanding, neither in 2000 nor today is it monoclonal antibodies, "magic bullet" drug-antibody conjugates, or cytokines that are making the difference-nor is it 
anti-angiogenic and anti-metastatic agents, which the cancer scientists of 1986 had high hopes for. Improvements are due to earlier diagnosis, better surgery, better radiotherapy, better hormonal and cytotoxic chemotherapy (including use in the adjuvant setting), and better supportive care.

The potential of cancer vaccines was also overestimated: $60 \%$ of those polled thought that by 2000 we would be vaccinating people "directly" against certain types of tumour-but we still have no effective vaccine treatment for established cancers. And, with the exception of a vaccine to prevent cervical cancer (approved in autumn 2006) and immunisation against hepatitis, we still have no vaccines against oncogenic viruses.

In short, oncologists in 1986 were remarkably accurate in predicting improvements in overall and

\author{
Correct and incorrect predictions \\ Oncology \\ Right \\ Two thirds of patients cured (alive five years after diagnosis) \\ Progress piecemeal \\ Best improvement in survival in breast cancer and with leukaemias and \\ lymphomas
}

No real change in cancers of lung, liver, pancreas, stomach, central nervous system

Wrong

Progress will come through antibodies, cytokines, vaccines

No real change in survival in colorectal cancer

\section{Cardiovascular disease}

Right

Thrombolysis becomes routine

Angioplasty takes off

Lipid metabolism research highly promising

Little potential for implantable heart

Little promise in minimising neuronal damage after stroke

\section{Wrong}

Decline in coronary artery bypass grafts

Nutritional advice improves problem of obesity

\section{Infectious diseases}

Right

Cumulative total of close to 1 million AIDS cases in US

Vaccines against hepatitis but not against herpes and malaria

No cure for common cold

\section{Wrong}

Safe and effective HIV vaccine by 2000

Cure generally available by 2010 (assuming chronic suppression of viral load does not count as cure)

\section{Nervous system}

Right

Little progress against Alzheimer's disease and Parkinson's disease Cognitive therapy used more

Reduction in tardive dyskinesia

\section{Wrong}

Fetal tissue transplants, and gene repair, accepted and effective Less dependence on opiates for severe pain tumour-specific survival, but for entirely the wrong reasons.

\section{Matters of the heart}

The clinical scientists were also prescient in cardiology, even when it came to identifying the precise means by which progress would be effected-unlike the oncologists. Perhaps precision as to means is easier when the problem is basically faulty plumbing rather than myriad derangements in the processes controlling cell division and differentiation.

Cardiovascular experts identified a bright future for thrombolytics: almost half rated their promise as 9 or 10 on a 10 point scale. This was bold.

The interviews took place six months after publication of the 12000 patient GISSI trial, which showed that patients with myocardial infarction treated with streptokinase had an 18\% reduction in mortality at 21 days. But this was two years before ISIS-2, which many regarded as the required confirmatory trial. In 1986, streptokinase was the only clotbuster available. Given the possibility of uncontrolled bleeding, many clinicians worried about the balance of risk and benefit; and even in 1988 there was still no consensus that thrombolysis should be routine. ${ }^{4}$

Those interviewed in 1986 were right about the limited potential of implanting an artificial heart: $90 \%$ said that transplants would be preferred for the foreseeable future. They were also correct in spotting balloon angioplasty as a technique with plenty of room for expansion. In 1993, angioplasties overtook coronary artery bypass grafting among Medicare patients, and now twice as many angioplasties (1.2 million) as coronary artery bypass grafts are performed annually in the US. ${ }^{5}{ }^{6}$ But panel members were not correct in thinking that the number of bypass grafts would show a corresponding sharp decline. Numbers rose steadily from 230000 in 1986 until peaking in 1997. Although bypass grafts have declined 10\% since then, half a million are still carried out each year. ${ }^{6}$

For coronary disease prevention, it's surprising that a third of those interviewed did not expect doctors in 2000 to be advising their patients to limit consumption of cholesterol. On the other hand, more than half rated research into lipid metabolism and transport as 7 or higher on the scale of future promise, a year before the first statin was licensed by the Food and Drug Administration.

Rather optimistically, 69\% thought that general nutritional advice would have improved the problem of obesity by 2000 . Asked about the likely health status of the population, the panel did not foresee burgeoning rates of overweight and associated problems such as diabetes and cardiovascular disease.

\section{HIV and other infections}

Biotechnology, cancer, and infection specialists were asked in 1986 how many people in the US would have developed AIDS by 2000. The median estimate was 1.1 million. The latest cumulative total (for 2004) is $944000 .{ }^{7}$ Given the many uncertainties of the time, the 1986 estimate was extraordinarily accurate. But the success of an HIV vaccine was overpredicted: $60 \%$ thought we'd have a safe and effective vaccine by now. 


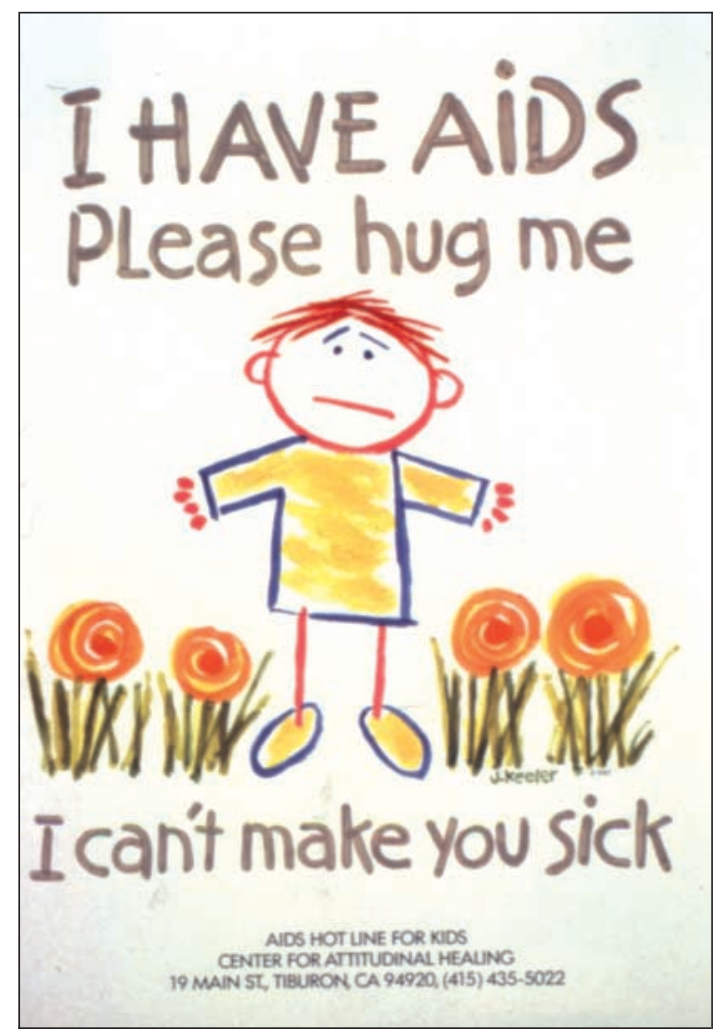

Predictions that a million people in the US would have AIDS by now were right, but predictions for an effective vaccine and curative treatment were wrong

It's difficult to judge whether the scientists were right about antiretroviral drugs: interviewees were asked to say when an "effective cure" would be "generally available." Does chronic suppression of viral load count as success? Did "general" availability include the developing world? Just over half (52\%) thought we'd have a generally available and effective cure by 2010 .

Perhaps because of the eradication of smallpox in 1977 , vaccines were accepted as the best way forward in combating infectious disease in general. Hepatitis was judged most likely to see significant advance, but not herpes or malaria. Right in all respects. The panel also did well in their forecast for measles: only $17 \%$ said there was a reasonable chance of eliminating the disease by 2000. Measles worldwide still causes half a million deaths each year. ${ }^{8}$

\section{Nervous system}

More than $80 \%$ of the neuroscientists interviewed thought that stimulating nerve cell growth and regeneration would be clinically viable by 2000 and that we would be using genetic engineering to treat inherited disorders. Seventy per cent predicted that fetal brain tissue transplants would be an accepted treatment and would be "very effective" for at least a few neurological conditions.

A lot closer to the mark were their expectations about how more traditional treatments might develop. The hope that a new generation of atypical antipsychotics would carry a much reduced risk of extrapyramidal side effects and tardive dyskinesia seems to have been realised, though there has recently been renewed debate about the latter. ${ }^{9}$ Those interviewed were right in thinking that traditional psychoanalysis would be a relatively unimportant element in the treatment of mental illness, but that use of cognitive therapy would increase. No one predicted a comeback for electroconvulsive therapy.

They were also right in thinking that any progress against Alzheimer's disease would, at best, be modest. Only 10\% thought we would be close to curing Parkinson's disease.

\section{Artificial bits and bobs}

Though the scientists were right in predicting that the next 15-20 years would see a greatly expanded role for artificial knees and hips, they were wrong in thinking that the same would be true for artificial wrists, ankles, toes, and fingers and artificial skin and blood. (In the mid-1980s, there had been a brief but well-publicised spurt of research into the idea that blood could be replaced by oxygen-carrying fluorocarbon emulsions. But the idea never came to much clinically.) The panel also had misplaced faith in the imminent importance of implantable drug infusion systems, and in a bright future for penile implants. No one in 1986 saw Viagra coming.

\section{Lessons for the future of futurology?}

It didn't take medical degrees a mile long to predict that the major health problems in the West would be those associated with ageing, or that malnutrition and infections would continue to plague the rest of the planet. Other questions must have required very careful consideration, and some, such as the cumulative number of AIDS cases in the US and the overall cure rate for cancer, were answered with surprising accuracy.

Where predictions erred, they did so by being overoptimistic. In predicting that vaccines would quickly be successful against HIV, clinical scientists were extrapolating from a history of solid achievement against other pathogens. But in predicting the widespread use by 2000 of cytokines, therapeutic antibodies, genetic engineering for inherited disorders, fetal tissue transplants and artificial blood, they were being carried away by the enthusiasms of the moment.

Whether this "flavour of the month effect" tells us something specific about medical scientists or something general about being human is an open question. But the demand for predictions will not dry up. Overall, what this set of crystal ball gazers got right is more surprising than what they got wrong.

Competing interests: None declared.

1 Taylor H. The Bristol-Myers report: medicine in the next century. New York: Louis Harris and Associates, 1987.

2 Centers for Disease Control and Prevention. Cancer survivorship. 9 July Centers for Disease Control and Prevention. Cance
2006. www.cdc.gov/cancer/survivorship/index.htm

3 Cancer Research UK. Trends in cancer survival rates. April 2005. http:// info.cancerresearchuk.org/cancerstats/survival/fiveyear/

4 Antman EM, Lau J, Kupelnick B, Mosteller F, Chalmers TC. A comparison of results of meta-analyses of randomized controlled trials and recommendations of clinical experts. JAMA 1992;268:240-8.

5 Lucas FL, DeLorenzo MA, Siewers AE, Wennberg DE. Temporal trends in the utilization of diagnostic testing and treatments for cardiovascular disease in the United States 1993-2001. Circulation 2006;113:374-9.

6 Treatment of coronary artery disease: what does rationing do? Washington: December 2005. (Brookings Institution policy brief No148.)

7 Centers for Disease Control and Prevention. Basic statistics. 16 October 2006. www.cdc.gov/hiv/topics/surveillance/basichtm

8 Centers for Disease Control and Prevention. Programs in brief: global Centers for Disease Control and Prevention.
health. www.cdc.gov/programs/global06.htm

9 Kane JM. Tardive dyskinesia circa 2006. Am J Psychiatry 2006;163:1316-8. 